Published in final edited form as:

Biomarkers. 2011 November ; 16(7): 590-599. doi:10.3109/1354750X.2011.611598.

\title{
The utility of naphthyl-keratin adducts as biomarkers for jet-fuel exposure
}

\author{
Juei-Chuan C. Kang-Sickel ${ }^{1}$, Mary Ann Butler ${ }^{2}$, Lynn Frame ${ }^{3}$, Berrin Serdar ${ }^{4}$, Yi-Chun E. \\ Chao $^{1}$, Peter Egeghy ${ }^{5}$, Stephen M. Rappaport ${ }^{6}$, Christine A. Toennis ${ }^{2}$, Wang Li ${ }^{7}$, Tatyana \\ Borisova $^{3}$, John E. French ${ }^{8}$, and Leena A. Nylander-French ${ }^{1}$ \\ ${ }^{1}$ Department of Environmental Sciences and Engineering, Gillings School of Global Public Health, \\ The University of North Carolina at Chapel Hill, Chapel Hill, NC, USA \\ 2Division of Applied Research and Technology, National Institute for Occupational Safety and \\ Health, Centers for Disease Control and Prevention, Cincinnati, OH, USA \\ ${ }^{3}$ Department of Pharmacology and Neuroscience, Texas Tech University Health Sciences \\ Center, Lubbock, TX, USA \\ ${ }^{4}$ Department of Environmental and Occupational Health, Colorado School of Public Health, \\ University of Colorado Denver, Aurora, Colorado, USA \\ ${ }^{5}$ US Environmental Protection Agency, National Exposure Research Laboratory, Human \\ Exposure and Atmospheric Sciences Division, Research Triangle Park, NC, USA \\ ${ }^{6}$ School of Public Health, University of California, Berkeley, CA, USA \\ ${ }^{7}$ Department of Internal Medicine, Texas Tech University Health Sciences Center, Lubbock, TX, \\ USA
}

${ }^{8}$ Host Susceptibility Branch, National Toxicology Program, The National Institute of Environmental Health Sciences, Research Triangle Park, NC, USA

\begin{abstract}
We investigated the association between biomarkers of dermal exposure, naphthyl-keratin adducts (NKA), and urine naphthalene biomarker levels in 105 workers routinely exposed to jet-fuel. A moderate correlation was observed between NKA and urine naphthalene levels $(p=0.061)$. The NKA, post-exposure breath naphthalene, and male gender were associated with an increase, while
\end{abstract}

\footnotetext{
(C) 2011 Informa UK, Ltd.

Address for Correspondence: Leena A. Nylander-French, Ph.D., CIH, Department of Environmental Sciences and Engineering, Gillings School of Global Public Health, The University of North Carolina at Chapel Hill, CB \#7431, Rosenau Hall, Chapel Hill, NC 27599-7431, USA. Tel: (919) 966-3826. Fax: (919) 966-7911. leena_french@unc.edu.

Declaration of interest

The authors report no conflicts of interest. Mention of company names and/or products does not constitute endorsement by the National Institute for Occupational Safety and Health. The findings and conclusions in this report are those of the authors and do not necessarily represent the views of the National Institute for Occupational Safety and Health. This work was supported by NIEHS (P42ES05948), NIOSH (T42/CCT422952 and T42/008673), and the NIEHS Intramural Research Program. It has been subjected to United States Environmental Protection Agency review and approved for publication. This article may be the work product of an employee or group of employees of the National Institute of Environmental Health Sciences (NIEHS), National Institutes of Health $(\mathrm{NIH})$; however, the statements, opinions or conclusions contained therein do not necessarily represent the statements, opinions or conclusions of NIEHS, NIH, or the United States government.
} 
CYP2E1*6 DD and GSTT1-plus (++/+-) genotypes were associated with a decrease in urine naphthalene level $(p<0.0001)$. The NKA show great promise as biomarkers for dermal exposure to naphthalene. Further studies are warranted to characterize the relationship between NKA, other exposure biomarkers, and/or biomarkers of biological effects due to naphthalene and/or PAH exposure.

\section{Keywords}

Biomarkers; CYP2E1; dermal exposure; glutathione S-transferase mu 1 (GSTM1); glutathione Stransferase theta 1 (GSTT1); jet fuel (JP-8); keratin adduct; NAD(P)H:quinone oxidoreductase (NQO1); 1-naphthol; 2-naphthol; naphthalene; urine

\section{Introduction}

Jet propulsion fuels (kerosene-based fuel mixtures) are standard fuels for commercial aviation as well as for military aircrafts and vehicles. Jet propulsion fuel type 8 (JP-8) is the battle field fuel for all U.S. military operations and was chosen to replace its predecessor JP-4 in 1972 by North Atlantic Treaty Organization (NATO) due to its higher flashpoint (ATSDR 1998; Zeiger \& Smith 1998; Carlton \& Smith 2000; NRC 2003). In addition, JP-8 is used as a degreaser, heat source, and cooking fuel by the U.S. military. It is estimated that 5 billion gallons of JP-8 is used by the U.S. military and NATO each year (NRC 2003). It has been recognized as the single largest source of chemical exposure for the military personnel (Carlton \& Smith 2000). Dermal exposure to jet fuel, along with inhalation exposure, was observed to contribute significantly to body burden in the U.S. Air Force (USAF) fuel-cell maintenance workers (Chao et al. 2006; Kim et al. 2007). In addition, due to its low vapor pressure and slower evaporation rate in comparison to its predecessor JP-4, increased duration of dermal contact with JP-8 presents increased risk for dermal exposure (Chao et al. 2005). Although JP-8 contains hundreds of aliphatic and aromatic hydrocarbons, naphthalene and its metabolites (1- and 2-naphthol) in urine have been established as effective surrogate biomarkers of exposure to JP-8 (Egeghy et al. 2003; Serdar et al. 2003; Serdar et al. 2004; Chao et al. 2006; Kim et al. 2007).

Accurate quantification of the contribution of dermal exposure to the systemic dose is required in order to complement and improve current exposure assessment models for longterm health effects of jet fuel exposure, a facet that is missing from current epidemiological research. Quantitation of the individual dermal dose and determination of the mechanism of action hinges upon development of biomarkers that can encompass both acute and chronic exposure and upon development of specific analytical procedures to quantitate these biomarkers. The only method for quantitation of dermal exposure to jet fuel (JP-8) reported to date measures the unmetabolized naphthalene (surrogate for JP-8) on the skin surface, which can only be attributed to recent exposure because of rapid absorption and biotransformation of naphthalene (Chao et al. 2005; Chao et al. 2006). Naphthalene metabolites bound to skin keratins would be appropriate as specific biomarkers for dermal exposure, as the bioactivation required for naphthalene metabolite adduction to keratin only occurs in the suprabasal layer of the epidermis (Kang-Sickel et al. 2008; Kang-Sickel et al. 
2010), where keratin is synthesized de novo and the non-living squame is formed (Watt 1988). Approximately 20-28 days are required for differentiation and maturation of suprabasal keratinocytes (Junqueira \& Carneiro 2005; Furukawa et al. 2008) to migrate from the basal layer to the surface to form the stratum corneum, which requires continuous replacement. Therefore, non-invasive sampling of stratum corneum by sequential tapestripping can be used to monitor an individual's past ( $<28$ days) exposure to naphthalenecontaining mixtures and characterize individual variation in dermal metabolic capacity and keratin adduction in human populations.

The potential contribution of dermal exposure to total JP- 8 exposure is suggested based on the correlation between the metabolite levels in urine (e.g. 1- and 2-naphthol) and various surrogates of dermal exposure, including skin irritation, work inside the fuel cell, and removing and cleaning fuel puddles (Egeghy et al. 2003; Serdar et al. 2004). However, these surrogate indicators provide only qualitative, not quantitative, information. We previously established that naphthalene (as a model polycyclic aromatic hydrocarbon) and its metabolites 1-naphthol (1NAP) and 2-naphthol (2NAP) in urine can be used as quantitative biomarkers of a complex jet fuel mixture exposure to the skin (Chao et al. 2006). We further established that dermal exposure to jet fuel, along with inhalation exposure, contributes significantly to the total body burden in the exposed USAF fuel-cell maintenance workers (Chao et al. 2005; Chao et al. 2006; Kim et al. 2007). We have also shown that highly specific polyclonal antibodies to naphthalene metabolites can be used for a sensitive enzyme-linked immunosorbent assay (ELISA) for quantification of NKAs as biomarkers of dermal exposure to jet fuel (Kang-Sickel et al. 2008; Kang-Sickel et al. 2010). In dermal tape-strip samples collected from 105 individuals exposed to JP-8, naphthyl-conjugated keratin peptides were detected at levels from 0.004 to $6.104 \mathrm{pmol}$ adduct $/ \mu \mathrm{g}$ keratin, but were undetectable in unexposed volunteers (Kang-Sickel et al. 2008; Kang-Sickel et al. 2010).

Our first objective was to characterize the association between biomarkers of dermal exposure (i.e., NKAs) and urine naphthalene and naphthalene metabolite levels in 105 fuelcell maintenance workers along with inhalation exposure as well as individual and work place factors that may contribute to these biomarker levels using multiple linear regression models. However, naphthalene and its metabolites are substrates for biotransformation enzymes, including cytochrome P-450s (CYPs), glutathione-S-transferases (GSTs), and NAD(P)H:quinone oxidoreductases (NQO1) (Buckpitt et al. 2002; Preuss et al. 2003; Waidyanatha et al. 2004a). Genetic polymorphisms account for interindividual differences in the expression of these enzymes and, thus, may contribute to the differences in biomarker levels and exposure-related toxicity. In the skin, as in the liver, metabolizing enzymes convert naphthalene to more polar metabolites but also catalyze the synthesis of reactive metabolites that bind to nucleophilic macromolecule (protein or DNA) to form adducts (Ross \& Nesnow 1993; Isbell et al. 2005; Shimada 2006; Saeed et al. 2009). Therefore, our second objective was to examine the potential contribution of genetic variants of four genes (CYP2E1, GSTM1, GSTT1, and NQO1), which code for biotransformation enzymes intrinsic to naphthalene metabolism, to the observed levels of NKAs and urine biomarkers in this worker population. 


\section{Materials and methods}

\section{Study population}

Exposure data were available from the broad exposure assessment and health effects study of the personnel exposed to JP-8 at six USAF bases in the continental United States (described in Egeghy et al. 2003; Chao et al. 2005; Chao et al. 2006). While 339 USAF personnel were enrolled in the overall study, 105 fuel-cell maintenance workers from five bases who were monitored for both dermal and systemic levels were included in this study. These workers serviced primarily F-series fighter jets or C-130 transporter jets. The workers comprised of 98 males (93.3\%) and 7 females (6.7\%), 92 Caucasians (87.6\%), and 13 nonCaucasians (African-American, Hispanic, or Asian; 12.4\%), and 46 were smokers (43.8\%). The average age of the workers was $24.7 \pm 5.0$ years and ranged from 18 to 40 years. Workers were recruited with informed consent from active duty USAF personnel who routinely worked with and were exposed to JP-8. This study was approved by the institutional review board of each of the participating investigators and for the USAF, and the study complied with all applicable U.S. requirements and regulations.

Questionnaires and work diaries were recorded after the work shift to obtain detailed information on demographic factors including age, ethnicity, gender, smoking status, job tasks and durations, use of personal protective equipment (PPE), and other work-related characteristics. Each of the workers had been assigned a priori into one of three exposure categories (high, moderate, low) based on the primary job tasks (Chao et al. 2005). Workers who entered fuel tanks (entrants) on the sampling day were classified as high-exposure group. The medium-exposure group consisted of workers who were attendants and/or runners assisting the entrants. Other field workers who had occasional contact with JP-8 were classified as the low-exposure group (Chao et al. 2005).

\section{Collection and analyses for skin, inhalation, and urine samples}

The collection of dermal tape-strip samples and analysis for naphthalene (Chao et al. 2005) and four NKA levels (Kang-Sickel et al. 2008; Kang-Sickel et al. 2010) have been described previously. Briefly, tape-strip samples were collected post-exposure using three sequential adhesive tape-strips in each site $\left(2.5 \mathrm{~cm} \times 4.0 \mathrm{~cm}\right.$, surface area $10 \mathrm{~cm}^{2}$; Cover-Roll ${ }^{\mathrm{TM}}$ tape, Beiersdorf AG, Germany) from three exposed body regions with potentially the greatest JP-8 exposure, as identified by the subject and confirmed via visual inspection by the investigators. In each site, side-by-side samples were collected, one set for determination of naphthalene level and the other set for determination of NKA level. Each tape was applied onto the skin surface with a constant pressure and removed at an approximately $45^{\circ}$ angle after $1 \mathrm{~min}$. For determination of naphthalene level, tape was folded and placed into a labeled scintillation vial containing $5 \mathrm{ml}$ acetone and $20 \mu \mathrm{L}$ of $25 \mu \mathrm{g} / \mathrm{mL}$ naphthalene- $\mathrm{d}_{8}$ (internal standard) and stored at $-80^{\circ} \mathrm{C}$ until analysis by gas chromatography-mass spectrometry (GC-MS). For determination of NKAs, tape was rolled with the adhesive side facing out and placed into a $2 \mathrm{~mL}$ cryovial and stored at $-80^{\circ} \mathrm{C}$ until the keratin from the tape sample was extracted and quantified by Bradford assay and four NKAs (1-naphthylkeratin-1, 2-naphthyl-keratin-1, 1-naphthyl-keratin-10, and 2-naphthyl-keratin-10) quantified by ELISA (Kang-Sickel et al. 2008). 
Inhalation exposure to naphthalene was monitored during the $4 \mathrm{~h}$ work shift using passive monitors attached to the workers' collars. End-exhaled breath samples were collected before and immediately after the work shift using $75 \mathrm{~cm}^{3}$ glass bulbs. The full-face supplied-air respirator was worn by 69 (100\%) of the a priori high-exposure group workers, while 10 (59\%) of medium-exposure and none of the low-exposure workers wore a respirator. Both breathing-zone air and breath samples were analyzed by thermal desorption followed by GC with photo-ionization detection, as described elsewhere (Egeghy et al. 2003). The collection of urine samples was performed before and after the work shift and the concentrations of the urine 1NAP and 2NAP were determined by GC-MS, as described elsewhere (Serdar et al. 2003).

\section{Genotyping for candidate genes}

A sample of whole blood was collected into a $10 \mathrm{~mL}$ EDTA tube (Vacutainer ${ }^{\circledR}$; BecktonDickinson and Company, Franklin Lakes, NJ, USA) for each worker at the beginning and at the end of the work shift. The samples were packed with Blue Ice ${ }^{\odot}$ (Rubbermaid, Atlanta, GA, USA) and shipped to arrive at the lab within $24 \mathrm{~h}$ at a temperature of $4^{\circ} \mathrm{C}$. Genomic DNA was isolated from nucleated blood cells for genotyping from $0.4 \mathrm{~mL}$ of whole blood using InstaGene Genomic DNA Kit (Cat \#732-6028, BioRad, Hercules, CA, USA). When additional DNA was needed for genotyping, genomic DNA was isolated from $0.3 \mathrm{~mL}$ of whole blood that had been stored at $-70^{\circ} \mathrm{C}$ using Gentra Puregene Blood Kit (Qiagen Sciences, Inc., Germantown, MD, USA) following the manufacturers procedures.

The CYP2E1 DraI (mutant allele: $C Y P 2 E^{*} 6$ ) restriction fragment length polymorphism was identified by minor modifications of methods described by Kato et al. (1995). Minor modifications of the CYP2E1 methods included using AmpliTaq Gold Polymerase and Applied Biosystems polymerase chain reaction (PCR) Buffer II in the reaction mixture and a 10 min preincubation of the reaction mixture at $95^{\circ} \mathrm{C}$ prior to beginning of the specified amplification program. The PCR amplification and restriction products were examined on $2 \%$ agarose E-gels (Invitrogen Life Technologies, Carlsbad, CA, USA) or 2\% agarose gels prepared in the laboratory containing ethidium bromide and visualized on an ultraviolet transilluminator. The CYP2E1 has a polymorphic DraI restriction site in intron six. The DraI restriction site is present in the CYP2E1 DraI Type D genotype, whereas the site is missing in the CYP2E1 DraI Type C genotype.

The GSTM1 genotyping was based on the method of Huang et al. (1997). The PCR reaction mixture contained thermophilic DNA polymerase 10X buffer with $15 \mathrm{mM} \mathrm{MgCl}_{2}, 2.5 \mathrm{pmol}$ of each dNTP primer, $20 \mu \mathrm{M}$ of each GSTM1 primer, $20 \mu \mathrm{M}$ of each $\beta$-globin primer, 2.75 $\mu \mathrm{L}$ Taq polymerase, and $2 \mu \mathrm{L}$ of DNA template (100-300 ng) in a total reaction volume of $50 \mu \mathrm{L}$. The reaction mixture was placed in a thermocycler (model PTC-100, MJ Research Inc., Waltham, MA, USA) for 30 cycles at $95^{\circ} \mathrm{C}$ for $30 \mathrm{~s}$ followed by $45 \mathrm{~s}$ at $56^{\circ} \mathrm{C}, 72^{\circ} \mathrm{C}$ for $45 \mathrm{~s}$, and a final step at $72^{\circ} \mathrm{C}$ for $10 \mathrm{~min}$. The PCR products were separated by electrophoresis on $2.5 \%$ agarose gels containing ethidium bromide and visualized on an ultraviolet transilluminator. The $\beta$-globin gene served as an internal control and generated a $100 \mathrm{bp}$ PCR product in all reaction tubes. Only genomic DNA from GST-positive individuals served as a template for amplification of an additional 273 bp product. 
The GSTT1 genotype was identified using primers described by Hirvonen et al. (1996). The PCR reaction mixture contained 1X Applied Biosystems PCR Buffer II, $2 \mathrm{mM} \mathrm{MgCl} 2,2.5$ pmol of each dNTP primer, 30 pmol of GSTT1 primer, 10 pmol of each $\beta$-globin primer, 1 unit AmpliTaq Gold Polymerase, and $2 \mu \mathrm{L}$ of DNA extract in a total reaction mixture of 30 $\mu \mathrm{L}$. The reaction mixture was placed in a thermocycler (model PTC-100, MJ Research Inc., Waltham, MA, USA) for $10 \mathrm{~min}$ at $95^{\circ} \mathrm{C}$ followed by 25 cycles of $94^{\circ} \mathrm{C}$ for $1 \mathrm{~min}, 59^{\circ} \mathrm{C}$ for $1 \mathrm{~min}, 72^{\circ} \mathrm{C}$ for $1.5 \mathrm{~min}$, and a final step of $72^{\circ} \mathrm{C}$ for $5 \mathrm{~min}$. The PCR products were examined as described for $C Y P 2 E 1$ above. The $\beta$-globin gene served as an internal control and generated a $100 \mathrm{bp}$ PCR product in all reaction tubes. The GSTT1-null individuals were identified by their DNA templates that produced no amplification with GSTT1 specific primer.

The method described by Wiemels et al. (1999), with minor modifications, was used to characterize the single nucleotide polymorphism rs1800566 in NQO1. Minor modifications in the NQO1 methods and examination of PCR amplification and restriction products were carried out as described for $C Y P 2 E 1$ above. This genetic variant has a $\mathrm{C}$ to $\mathrm{T}$ transition in nucleotide 609 in exon 6 of NQO1 (Guha et al. 2008).

Duplicate reactions for all genotypes were conducted on a minimum of $20 \%$ of the participants and all duplicate results were in complete concordance.

\section{Statistical analyses}

All statistical analyses were conducted using the SAS software (Version 9.1.3, SAS Institute, Cary, NC, USA) at a significance level of 0.10. All exposure and biomarker data (NKA levels, dermal, breathing-zone air, and breath naphthalene levels, as well as urine naphthalene and naphthol levels) were natural log-transformed to satisfy normality assumptions prior to statistical analyses. All statistical models were constructed and analyses conducted based on subjects with available data points; therefore, the sample sizes in these analyses differed due to missing values of independent variables.

The total NKA level for each worker was calculated by summing the four keratinnormalized adduct levels measured in all sampling sites. Pearson correlation was examined between the total NKA level and JP-8 exposure measures (i.e. dermal, breathing-zone, preand post-exposure breath naphthalene levels) and urine biomarkers [i.e. naphthalene, 1NAP, $2 \mathrm{NAP}$, and total naphthol $(\mathrm{TNAP}=1 \mathrm{NAP}+2 \mathrm{NAP})$ levels $]$. Analysis of variance (ANOVA) with the significance level of 0.1 was performed to test the effects of genetic variants in four metabolic genes (CYP2E1, GSTM1, GSTT1, and NQO1), which have been indicated in naphthalene metabolism (Tingle \& Park 1993; Wilson et al. 1996; Yang et al. 1999; Lee et al. 2001), on the levels of total NKAs and urine biomarkers observed in this worker population.

Multiple linear-regression analyses were conducted to examine workplace and personal factors contributing to total NKA levels in all workers and in a priori determined highexposure group upon jet fuel exposure. Stepwise variable selection was used to determine final regression models, with $a=0.10$ as the inclusion level for predictors. The basic multiple linear regression model was as follows: 


$$
Y_{i}=\alpha+\sum_{j=1}^{J} \beta_{j} X_{i j}+\sum_{k=1}^{K} \gamma_{k} C_{i k}+\varepsilon_{i}
$$

where $Y_{i}$ is the natural log-transformed total NKA level measured in the $i$ th worker's tapestrip samples; $a$ is the intercept; $X_{i j}$ represents the $i$ th worker's $j$ th dermal naphthalene level; $C_{i k}$ represents the $k$ th covariate value for the $i$ th worker based on work diary and questionnaire, including exposure duration, job task, PPE, age, gender, and smoking status, as well as metabolic genotypes CYP2E1, GSTM1, GSTT1, and NQO1.

A second multiple linear regression analysis was used to investigate the relationship between the urine biomarkers and the total NKA levels as well as the contribution of the covariates also analyzed in model 1 . Again, the models were constructed separately for all workers and for the a priori determined high-exposure group only. The basic multiple linear regression model was as follows:

$$
Y_{i}=\alpha+\sum_{j=1}^{J} \beta_{j} X_{i j}+\sum_{k=1}^{K} \gamma_{k} C_{i k}+\varepsilon_{i}
$$

where $Y_{i}$ is the natural log-transformed urine biomarker level, measured in the $i$ th worker's urine samples; $a$ is the intercept; $X_{i j}$ represents the $i$ th worker's $j$ th total NKA level; $C_{i k}$ represents the $k$ th covariate value for the $i$ th worker, which included exposure data, PPE, metabolic genotypes CYP2E1, GSTM1, GSTT1, and NQO1, age, ethnicity, gender, and smoking status. Collinearity was examined for all models using variance inflation, condition indices, and eigenvalues. Possible outliers were examined by studentized residuals.

\section{Results}

No significant correlation was observed between the total NKA levels and various exposure measures (i.e. dermal, breath, and breathing-zone naphthalene levels) or with the urine 1NAP, 2NAP, or TNAP levels with the exception of urine naphthalene level (Pearson correlation $r=0.184, p=0.061$ ) (Table 1).

The association between biomarker levels (i.e. total NKA level and urine 1NAP, 2NAP, TNAP, or naphthalene level) and the genotype of each of the four genes (CYP2E1, GSTM1, GSTT1, and NQO1) are presented in Table 2. A significant difference in total NKA level was observed between individuals with GSTT1-null genotype and those with at least one copy of GSTT1 gene [GSTT1-plus (++/+-)] ( $p=0.080)$. Individuals carrying NQOI homozygous variant (TT) also had significantly lower keratin adduct levels than those with homozygous wild-type (CC) $(p=0.085)$.

The regression analysis showed that total NKA level was influenced by dermal naphthalene level (lndermal), duration of exposure on the sampling day (exposure duration), and age (Table 3). The dermal naphthalene level and the age of the worker were inversely associated with total NKA level, while exposure duration increased total NKA levels. When we investigated the factors related to workers assigned into the a priori high-exposure group 
only ( $n=68)$, these same three predictors as for all workers were observed to be significant (Table 3). None of the four metabolic genotypes were observed to be significantly associated with total NKA level in either multiple linear-regression analysis when other significant covariates were included in the models.

Based on the Pearson correlation results (Table 1), a second regression model was constructed using urine naphthalene as the outcome variable. The significant predictors for urine naphthalene levels were total NKA level, post-exposure breath naphthalene level (lnpost-breath), CYP2E1*6 DD (wild type) genotype, presence of one or both copies of GSTT1 gene (++/+-), and gender (Table 4). The total NKA level, post-exposure breath naphthalene level, and male gender were associated with an increase in the urine naphthalene level, while the CYP2El*6 DD genotype and the presence of one or both copies of GSTT1 gene (++/+-) were associated with a decrease in urine naphthalene level. When this analysis was limited to the workers in the a priori high-exposure group $(n=64), 24.5 \%$ of the total variance in the urine naphthalene level was explained by the total NKA and postexposure breath naphthalene levels as well as presence of GSTT1 genotype.

\section{Discussion}

Previously, we demonstrated the human skin's capacity to express enzymes for xenobiotic metabolism and to form NKAs in response to naphthalene exposure (Kang-Sickel et al. 2008; Kang-Sickel et al. 2010). We also demonstrated that these adducts can be quantitatively measured in the exposed skin of workers, facilitating naphthalene exposure assessment, particularly in regard to the dermal route (Kang-Sickel et al. 2008; Kang-Sickel et al. 2010). In addition, inhalation and dermal exposure were identified as significant factors contributing to the total systemic dose of naphthalene, measured as urine naphthol levels, in workers exposed to jet fuel (Serdar et al. 2004; Chao et al. 2006; Kim et al. 2007). Similarly, urine naphthalene was identified as a biomarker for both dermal and inhalation exposure to polycyclic aromatic hydrocarbons (PAHs) (Campo et al. 2009; Sobus et al. 2009a; Sobus et al. 2009b).

Here, we examined the relationship between the total skin NKA levels and urine biomarkers of naphthalene exposure, as a surrogate for JP-8 exposure. We observed a significant correlation between total NKA and urine naphthalene levels $(r=0.184, p=0.061)$ but not between total NKA and breath naphthalene or urine naphthol levels. Jet fuel workers who entered and worked in the fuel tanks were equipped with in-line respirators and cotton coveralls. In this study, $75 \%$ of the fuel-cell maintenance workers (79/105) wore full-face supplied-air respirators. Thus, the principal route of contact and exposure to naphthalene is expected to be dermal. The NKA in the skin are formed via metabolism in the suprabasal layer of the skin (Kang-Sickel et al. 2010) and manifested after the processes of keratinocyte maturation, proliferation, differentiation, and migration to the surface of stratum corneum, which take approximately 28 days (Junqueira \& Carneiro 2005; Furukawa et al. 2008). Since each tape-strip removes approximately 1 layer of stratum corneum (i.e. three sequential tape-strips remove approximately three layers) and based on the average keratinocyte maturation and differentiation processes for a healthy individual, the measured total NKA levels reflect dermal exposure that occurred approximately 3-4 weeks prior to 
sampling. Once naphthalene is metabolized into reactive naphthalene-1,2-oxide and the keratin adduction occurred in the skin, the intermediate reactive metabolites do not go through the nonenzymatic rearrangement and enter the system circulation as 1NAP or 2NAP to be further metabolized or excreted. If the individual's metabolic capacity in the skin became saturated, excess naphthalene would appear in the blood and enter the systemic circulation (Kim et al. 2006a, Kim et al. 2006b). Distribution would favor the kidneys due to the rates of perfusion. Metabolism of naphthalene could occur in the kidney cortex and outer medulla. Urine 1NAP and 2NAP levels reflect metabolism in both the epidermis and the kidney and, to a lesser extent, the liver. Exhaled or urine naphthalene levels observed at the end of the workday reflect the total excess naphthalene in the systemic circulation.

Therefore, the stronger associations for the parent compound (naphthalene) than for naphthol metabolites in urine suggest that the levels of dermal exposure exceeded the skin's capacity to metabolize naphthalene.

The lack of association between the skin NKA levels and the breath naphthalene or urine naphthol levels is likely due to the fact that the inhalation exposure to jet fuel was overestimated ( $75 \%$ of the workers uses in-line respirators) and, thus, the relative contribution of dermal exposure to the systemic exposure was increased. This lack of association may also be partially due to the differences in the biological half-lives of parent compound and its metabolites in different tissues/organs, and their representations of different exposure windows (Ruchirawa et al. 2002). For example, the half-life of naphthalene in breath is estimated to be 22 min (Egeghy et al. 2003), while half-lives for urine naphthols are 1.2-4.6 h in a rapid phase, and 14-46 h in a slow phase (Bieniek 1994; Heikkila et al. 1995).

Our results indicating the lack of correlation between breath and urine biomarkers and skin protein adducts is supported by previously published studies on various urine biomarkers and protein adduct levels in regard to PAH exposure. Omland et al. (1994) observed no correlation between the levels of benzo(a)pyrene-albumin adducts and 1-hydroxypyrene (1HP), a urinary biomarker for PAH exposure, in iron foundry workers. No correlation was observed between 1-HP and DNA or serum protein adducts in traffic police in Bangkok and Thailand, in Danish foundry workers, in Hungarian aluminum plant workers, or in Danish bus and postal workers, and garage workers (Sherson et al. 1992; Nielsen et al. 1996; Autrup et al. 1999; Schoket et al. 1999; Ruchirawa et al. 2002). In addition, in our study the exposure intensity from one-day measurements may not have represented the exposure that occurred during the past 20-28 days, as measured by the keratin adduct levels, that the worker experienced. Therefore, the potential for this lack of correlation was expected.

Using multiple linear regression models in order to consider both environmental and genetic factors, we observed that the total NKA levels measured in the skin of fuel-cell maintenance workers were positively associated with exposure duration but inversely associated with the measured dermal naphthalene level and age. Interestingly, we observed previously that exposure duration was associated with lower dermal naphthalene level (Chao et al. 2005). According to our study protocol, the subjects were to work for $4 \mathrm{~h}$ and then return to the examination station at the end of the work shift. Thus, the exposure duration was defined as the time between starting work and dermal sampling. Due to the lag-time between exposure 
and dermal sampling as well as the relatively fast dermal penetration rate of naphthalene, as duration of exposure increased, more naphthalene was absorbed into the stratum corneum, and metabolized by keratinocytes to form keratin adducts. Thus, less naphthalene remained on the surface of the stratum corneum for sampling by tape-stripping.

Based on the coefficient of age on the total NKA level ( -0.019 for all workers and -0.022 for high-exposed group; Table 3), the data suggest an approximate $2 \%$ reduction of naphthalene metabolisms in skin with each year of age increase in this subject population. This finding is consistent with a 3\% reduction in naphthoquinone-albumin adduct level, and $2 \%$ reduction in 1,4-benzoquinone-albumin adduct level per year of increase in workers exposed to PAHs (Rappaport et al. 2002; Waidyanatha et al. 2004b). Experimental evidence also suggests that percutaneous absorption of some chemicals decrease with increasing age (Christophers \& Kligman 1965; Tagami 1972; Roskos et al. 1989). This change may be due to the lower water and lipid contents in aged skin compared to young skin, which may account for decreased skin permeability (Blank \& McAuliffe 1985) and partitioning of exogenous chemicals into the stratum corneum.

Because naphthalene is metabolized by phases I and II enzymes (Buckpitt et al. 2002; Preuss et al. 2003; Waidyanatha et al. 2004a), we examined the effects of four metabolic genotypes (CYP2E1, GSTM1, GSTT1, and NQOI) on the measured total NKA levels in the skin and on the urine biomarker levels (Table 2). We also examined the effects of these genotypes on the total NKA (Table 3) and the urine naphthalene levels (Table 4) using linear regression modeling by considering both personal and environmental factors.

Higher levels of DNA adducts and urine naphthols have been observed in GSTM1-null in comparison to the GSTM1-plus individuals who were exposed to PAHs (Yang et al. 1999; Lee et al. 2001; Pavanello et al. 2008). However, our results indicated that GSTM1 was not a significant contributing factor for keratin adduct or urine biomarkers levels (Table 2). In addition, GSTM1 genotype was not observed to have an effect on dermal exposure, as measured by keratin adduct levels (Table 3), or systemic dose, as measured by urine naphthalene levels (Table 4), when other significant factors were accounted for in the multiple linear regression analyses.

Our results showed that individuals with GSTT1-plus (++/+-) genotype had significantly higher total NKA levels than the GSTT1-null individuals ( $p=0.080$ ) (Table 2). However, the effects of GSTT1 became insignificant in regard to total NKA levels once other personal and environmental factors were considered in the linear regression model (Table 3). Interestingly, GSTT1-plus (++/+-) genotype was negatively associated with the urine naphthalene levels in the linear regression model (Table 4). No significant association between GSTT1 genotype and naphthalene metabolism has been observed (Lee et al. 2001; Nan et al. 2001). In other studies, individuals with GSTT1-null genotype were observed to have higher risk for benzene toxicity (Wan et al. 2002) and bladder cancer (Hung et al. 2004). On the contrary, Garte et al. (2007) observed a protective effect due to GSTT1-null genotype in regard to DNA damage. Our results and the conflicting data in the scientific literature indicate the lack of understanding of the involvement of GST in naphthalene metabolism and the complexity of investigating individual susceptibility factors in the 
context of environmental/occupational exposure. The effect sizes of the personal and environmental factors, such as exposure duration and dermal naphthalene level, may outweigh the effect associated with these metabolic genotypes. A single polymorphism may have only a weak effect, while susceptibility may be derived from effects of multiple genes, and the interaction from genes and the environment (Hung et al. 2004).

The second multiple linear regression model showed that urine naphthalene level increased as the total NKA and post-exposure breath naphthalene levels increased (Table 4). This observation also suggests that jet fuel exposure was sufficient to saturate the body's metabolic capacity since more naphthalene is being excreted without being metabolized. The induction of $C Y P 2 E 1$ is known to increase the formation of naphthols from naphthalene, and the polymorphisms in this gene are associated with urine 2NAP levels in Korean coke oven workers, who were exposed to PAHs via both inhalation and dermal routes (Wilson et al. 1996; Nan et al. 2001). Therefore, the inverse association between CYP2E $1 * 6$ wild-type (DD) and the urine naphthalene levels was expected. Interestingly, the same association was not observed in the model constructed with a priori high-exposure group. It is possible that in the high-exposure group, the metabolic capacity of CYP2E1 had been reached, which prevented observation of a significant effect of its genotypes on urinary naphthalene levels in this subject population.

In conclusion, this is the first study to investigate the contribution of both environmental and genetic factors in regard to the formation of skin keratin adducts and the relationships between total NKA levels and other JP-8 exposure biomarkers in occupationally exposed workers. Only naphthalene through dermal route of exposure can induce formation of NKAs in the skin (i.e. these adducts are route-specific indicators of exposure; inhalation exposure will not contribute to the formation of these adducts). Therefore, quantitation of naphthylkeratin protein adducts in the skin of jet fuel-exposed individuals allows us to investigate the importance of dermal exposure, penetration, metabolism, and adduction of naphthalene and to predict more accurately the contribution of chronic dermal exposure to total body burden for use in exposure assessment models. The total NKA levels were affected by both the work scenarios and extrinsic and intrinsic personal factors, and were associated with the urine naphthalene levels, indicating their potential as quantitative biomarkers of dermal exposure. In addition, this novel dermal exposure biomarker represents the past exposure that occurred 20-28 days prior to sampling, and can be utilized in exposure assessment for other common PAHs and environmental pollutants. Further studies are needed in regard to the relationship between skin NKAs, biological effect markers, and JP-8 health effects to further explore the potential application of these adducts as biomarkers of naphthalene exposure and related health effects.

\section{Acknowledgments}

We are especially grateful to the workers for their participation in the study. The United States Environmental Protection Agency through its Office of Research and Development collaborated in the research described here. 


\section{References}

ATSDR. Toxicological Profile for Jet Fuels JP-5 and JP-8. Atlanta: Agency for Toxic Substances and Disease Registry, Public Health Service, U.S. Department of Health and Human Services; 1998.

Autrup H, Daneshvar B, Dragsted LO, Gamborg M, Hansen M, Loft S, Okkels H, Nielsen F, Nielsen PS, Raffn E, Wallin H, Knudsen LE. Biomarkers for exposure to ambient air pollution-comparison of carcinogen-DNA adduct levels with other exposure markers and markers for oxidative stress. Environ Health Perspect. 1999; 107:233-238. [PubMed: 10064554]

Bieniek G. The presence of 1-naphthol in the urine of industrial workers exposed to naphthalene. Occup Environ Med. 1994; 51:357-359. [PubMed: 8199689]

Blank IH, McAuliffe DJ. Penetration of benzene through human skin. j Invest Dermatol. 1985; 85:522-526. [PubMed: 4067326]

Buckpitt A, Boland B, Isbell M, Morin D, Shultz M, Baldwin R, Chan K, Karlsson A, Lin C, Taff A, West J, Fanucchi M, Van Winkle L, Plopper C. Naphthalene-induced respiratory tract toxicity: metabolic mechanisms of toxicity. Drug Metab Rev. 2002; 34:791-820. [PubMed: 12487150]

Campo L, Mercadante R, Rossella F, Fustinoni S. Quantification of 13 priority polycyclic aromatic hydrocarbons in human urine by headspace solid-phase microextraction gas chromatographyisotope dilution mass spectrometry. Anal Chim Acta. 2009; 631:196-205. [PubMed: 19084626]

Carlton GN, Smith LB. Exposures to jet fuel and benzene during aircraft fuel tank repair in the U.S. Air Force. Appl Occup Environ Hyg. 2000; 15:485-491. [PubMed: 10853289]

Chao YC, Gibson RL, Nylander-French LA. Dermal exposure to jet fuel (JP-8) in US Air Force personnel. Ann Occup Hyg. 2005; 49:639-645. [PubMed: 16006502]

Chao YC, Kupper LL, Serdar B, Egeghy PP, Rappaport SM, Nylander-French LA. Dermal exposure to jet fuel JP-8 significantly contributes to the production of urinary naphthols in fuel-cell maintenance workers. Environ Health Perspect. 2006; 114:182-185. [PubMed: 16451852]

Christophers, E.; Kligman, AM. Percutaneous absorption in aged skin. In: Montagna, W., editor. Advances in Biology of Skin. Aging. Oxford: Pergamon Press; 1965. p. 163-175.

Egeghy PP, Hauf-Cabalo L, Gibson R, Rappaport SM. Benzene and naphthalene in air and breath as indicators of exposure to jet fuel. Occup Environ Med. 2003; 60:969-976. [PubMed: 14634191]

Furukawa F, Kanehara S, Harano F, Shinohara S, Kamimura J, Kawabata S, Igarashi S, Kawamura M, Yamamoto Y, Miyachi Y. Effects of adenosine 5'-monophosphate on epidermal turnover. Arch Dermatol Res. 2008; 300:485-493. [PubMed: 18758798]

Garte S, Taioli E, Popov T, Kalina I, Sram R, Farmer P. Role of GSTT1 deletion in DNA oxidative damage by exposure to polycyclic aromatic hydrocarbons in humans. Int j Cancer. 2007; 120:2499-2503. [PubMed: 17330842]

Guha N, Chang JS, Chokkalingam AP, Wiemels JL, Smith MT, Buffler PA. NQO1 polymorphisms and de novo childhood leukemia: a HuGE review and meta-analysis. Am j Epidemiol. 2008; 168:1221-1232. [PubMed: 18945694]

Heikkilä P, Luotamo M, Pyy L, Riihimäki V. Urinary 1-naphthol and 1-pyrenol as indicators of exposure to coal tar products. Int Arch Occup Environ Health. 1995; 67:211-217. [PubMed: 7591181]

Hirvonen A, Saarikoski ST, Linnainmaa K, Koskinen K, Husgafvel-Pursiainen K, Mattson K, Vainio H. Glutathione S-transferase and $\mathrm{N}$-acetyltransferase genotypes and asbestos-associated pulmonary disorders. j Natl Cancer Inst. 1996; 88:1853-1856. [PubMed: 8961976]

Huang CY, Huang KL, Cheng TJ, Wang JD, Hsieh LL. The GST T1 and CYP2E1 genotypes are possible factors causing vinyl chloride induced abnormal liver function. Arch Toxicol. 1997; 71:482-488. [PubMed: 9248625]

Hung RJ, Boffetta P, Brennan P, Malaveille C, Gelatti U, Placidi D, Carta A, Hautefeuille A, Porru S. Genetic polymorphisms of MPO, COMT, MnSOD, NQO1, interactions with environmental exposures and bladder cancer risk. Carcinogenesis. 2004; 25:973-978. [PubMed: 14729580]

Isbell MA, Morin D, Boland B, Buckpitt A, Salemi M, Presley J. Identification of proteins adducted by reactive naphthalene metabolites in vitro. Proteomics. 2005; 5:4197-4204. [PubMed: 16206326]

Junqueira, LC.; Carneiro, J. Basic Histology: Text and Atlas. Vol. 11. New York: McGraw-Hill, Medical Publishing Division; 2005. Epidermis; p. 360-372. 
Kang-Sickel JC, Fox DD, Nam TG, Jayaraj K, Ball LM, French JE, Klapper DG, Gold A, NylanderFrench LA. S-arylcysteine-keratin adducts as biomarkers of human dermal exposure to aromatic hydrocarbons. Chem Res Toxicol. 2008; 21:852-858. [PubMed: 18361511]

Kang-Sickel JC, Stober VP, French JE, Nylander-French LA. Exposure to naphthalene induces naphthyl-keratin adducts in human epidermis in vitro and in vivo. Biomarkers. 2010; 15:488-497. [PubMed: 20500019]

Kato S, Onda M, Matsukura N, Tokunaga A, Tajiri T, Kim DY, Tsuruta H, Matsuda N, Yamashita K, Shields PG. Cytochrome P4502E1 (CYP2E1) genetic polymorphism in a case-control study of gastric cancer and liver disease. Pharmacogenetics. 1995; 5(Spec No):S141-S144. [PubMed: 7581484]

Kim D, Andersen ME, Chao YC, Egeghy PP, Rappaport SM, Nylander-French LA. PBTK modeling demonstrates contribution of dermal and inhalation exposure components to end-exhaled breath concentrations of naphthalene. Environ Health Perspect. 2007; 115:894-901. [PubMed: 17589597]

Kim D, Andersen ME, Nylander-French LA. Dermal absorption and penetration of jet fuel components in humans. Toxicol Lett. 2006; 165:11-21. [PubMed: 16497449]

Kim D, Andersen ME, Nylander-French LA. A dermatotoxicokinetic model of human exposures to jet fuel. Toxicol Sci. 2006; 93:22-33. [PubMed: 16801332]

Lee CY, Lee JY, Kang JW, Kim H. Effects of genetic polymorphisms of CYP1A1, CYP2E1, GSTM1, and GSTT1 on the urinary levels of 1-hydroxypyrene and 2-naphthol in aircraft maintenance workers. Toxicol Lett. 2001; 123:115-124. [PubMed: 11641039]

Nan HM, Kim H, Lim HS, Choi JK, Kawamoto T, Kang JW, Lee CH, Kim YD, Kwon EH. Effects of occupation, lifestyle and genetic polymorphisms of CYP1A1, CYP2E1, GSTM1 and GSTT1 on urinary 1-hydroxypyrene and 2-naphthol concentrations. Carcinogenesis. 2001; 22:787-793. [PubMed: 11323399]

Nielsen PS, de Pater N, Okkels H, Autrup H. Environmental air pollution and DNA adducts in Copenhagen bus drivers-effect of GSTM1 and NAT2 genotypes on adduct levels. Carcinogenesis. 1996; 17:1021-1027. [PubMed: 8640907]

NRC. Toxicologic assessment of jet-propulsion fuel 8. Washington, DC: The National Academies Press; 2003.

Omland O, Sherson D, Hansen AM, Sigsgaard T, Autrup H, Overgaard E. Exposure of iron foundry workers to polycyclic aromatic hydrocarbons: benzo(a)pyrene-albumin adducts and 1hydroxypyrene as biomarkers for exposure. Occup Environ Med. 1994; 51:513-518. [PubMed: 7951774]

Pavanello S, Pulliero A, Clonfero E. Influence of GSTM1 null and low repair XPC PAT+ on anti$\mathrm{B}$ [a]PDE-DNA adduct in mononuclear white blood cells of subjects low exposed to PAHs through smoking and diet. Mutat Res. 2008; 638:195-204. [PubMed: 18035379]

Preuss R, Angerer J, Drexler H. Naphthalene-an environmental and occupational toxicant. Int Arch Occup Environ Health. 2003; 76:556-576. [PubMed: 12920524]

Rappaport SM, Waidyanatha S, Qu Q, Shore R, Jin X, Cohen B, Chen LC, Melikian AA, Li G, Yin S, Yan H, Xu B, Mu R, Li Y, Zhang X, Li K. Albumin adducts of benzene oxide and 1,4benzoquinone as measures of human benzene metabolism. Cancer Res. 2002; 62:1330-1337. [PubMed: 11888901]

Roskos KV, Maibach HI, Guy RH. The effect of aging on percutaneous absorption in man. $\mathrm{j}$ Pharmacokinet Biopharm. 1989; 17:617-630. [PubMed: 2635737]

Ross JA, Nesnow S. 32P-postlabelling in studies of polycyclic aromatic hydrocarbon activation. iarc Sci Publ. 1993; (124):71-78. [PubMed: 8225511]

Ruchirawa M, Mahidol C, Tangjarukij C, Pui-ock S, Jensen O, Kampeerawipakorn O, Tuntaviroon J, Aramphongphan A, Autrup H. Exposure to genotoxins present in ambient air in Bangkok, Thailand-particle associated polycyclic aromatic hydrocarbons and biomarkers. Sci Total Environ. 2002; 287:121-132. [PubMed: 11883753]

Saeed M, Higginbotham S, Gaikwad N, Chakravarti D, Rogan E, Cavalieri E. Depurinating naphthalene-DNA adducts in mouse skin related to cancer initiation. Free Radic Biol Med. 2009; 47:1075-1081. [PubMed: 19619639] 
Schoket B, Poirier MC, Mayer G, Török G, Kolozsi-Ringelhann A, Bognár G, Bigbee WL, Vincze I. Biomonitoring of human genotoxicity induced by complex occupational exposures. Mutat Res. 1999; 445:193-203. [PubMed: 10575430]

Serdar B, Egeghy PP, Gibson R, Rappaport SM. Dose-dependent production of urinary naphthols among workers exposed to jet fuel (JP-8). Am j Ind Med. 2004; 46:234-244. [PubMed: 15307122]

Serdar B, Egeghy PP, Waidyanatha S, Gibson R, Rappaport SM. Urinary biomarkers of exposure to jet fuel (JP-8). Environ Health Perspect. 2003; 111:1760-1764. [PubMed: 14594628]

Sherson D, Sigsgaard T, Overgaard E, Loft S, Poulsen HE, Jongeneelen FJ. Interaction of smoking, uptake of polycyclic aromatic hydrocarbons, and cytochrome P450IA2 activity among foundry workers. Br j Ind Med. 1992; 49:197-202. [PubMed: 1554617]

Shimada T. Xenobiotic-metabolizing enzymes involved in activation and detoxification of carcinogenic polycyclic aromatic hydrocarbons. Drug Metab Pharmacokinet. 2006; 21:257-276. [PubMed: 16946553]

Sobus JR, McClean MD, Herrick RF, Waidyanatha S, Nylander-French LA, Kupper LL, Rappaport SM. Comparing urinary biomarkers of airborne and dermal exposure to polycyclic aromatic compounds in asphalt-exposed workers. Ann Occup Hyg. 2009; 53:561-571. [PubMed: 19602502]

Sobus JR, McClean MD, Herrick RF, Waidyanatha S, Onyemauwa F, Kupper LL, Rappaport SM. Investigation of PAH biomarkers in the urine of workers exposed to hot asphalt. Ann Occup Hyg. 2009; 53:551-560. [PubMed: 19602500]

Tagami H. Funtional chracteristics of aged skin. 1. Percutaneous absorption. Acta DermatoVenereologica. 1972; 67:19-21.

Tingle MD, Park BK. The use of a three compartment in vitro model to investigate the role of hepatic drug metabolism in drug-induced blood dyscrasias. Br j Clin Pharmacol. 1993; 36:31-38. [PubMed: 8373710]

Waidyanatha S, Rothman N, Li G, Smith MT, Yin S, Rappaport SM. Rapid determination of six urinary benzene metabolites in occupationally exposed and unexposed subjects. Anal Biochem. 2004; 327:184-199. [PubMed: 15051535]

Waidyanatha S, Zheng Y, Serdar B, Rappaport SM. Albumin adducts of naphthalene metabolites as biomarkers of exposure to polycyclic aromatic hydrocarbons. Cancer Epidemiol Biomarkers Prev. 2004; 13:117-124. [PubMed: 14744742]

Wan J, Shi J, Hui L, Wu D, Jin X, Zhao N, Huang W, Xia Z, Hu G. Association of genetic polymorphisms in CYP2E1, MPO, NQO1, GSTM1, and GSTT1 genes with benzene poisoning. Environ Health Perspect. 2002; 110:1213-1218. [PubMed: 12460800]

Watt FM. Proliferation and terminal differentiation of human epidermal keratinocytes in culture. Biochem Soc Trans. 1988; 16:666-668. [PubMed: 2466709]

Wiemels JL, Pagnamenta A, Taylor GM, Eden OB, Alexander FE, Greaves MF. A lack of a functional $\mathrm{NAD}(\mathrm{P}) \mathrm{H}$ :quinone oxidoreductase allele is selectively associated with pediatric leukemias that have MLL fusions. United Kingdom Childhood Cancer Study Investigators. Cancer Res. 1999; 59:4095-4099. [PubMed: 10463613]

Wilson AS, Davis CD, Williams DP, Buckpitt AR, Pirmohamed M, Park BK. Characterisation of the toxic metabolite(s) of naphthalene. Toxicology. 1996; 114:233-242. [PubMed: 8980712]

Yang M, Koga M, Katoh T, Kawamoto T. A study for the proper application of urinary naphthols, new biomarkers for airborne polycyclic aromatic hydrocarbons. Arch Environ Contam Toxicol. 1999; 36:99-108. [PubMed: 9828267]

Zeiger E, Smith L. The first international conference on the environmental health and safety of jet fuel. Environ Health Perspect. 1998; 106:763-764. [PubMed: 9799193] 
Table 1

Pearson correlation coefficients $(r)$ between the total skin NKA levels [ln(ng adduct/ $/$ g keratin)] and the exposure and biomarker levels observed in the fuel-cell maintenance workers exposed to jet fuel.

\begin{tabular}{lcrc}
\hline Exposure or biomarker & $\boldsymbol{n}$ & Pearson correlation $(\boldsymbol{r})$ & $\boldsymbol{p}$-value \\
\hline Dermal naphthalene $\left(\mathrm{ng} / \mathrm{m}^{2}\right)$ & 105 & -0.038 & 0.704 \\
Pre-exposure breath naphthalene $\left[\mathrm{ln}\left(\mathrm{ng} / \mathrm{m}^{3}\right)\right]$ & 103 & 0.149 & 0.133 \\
Post-exposure breath naphthalene $\left(\mathrm{ng} / \mathrm{m}^{3}\right)$ & 101 & 0.038 & 0.707 \\
Breathing-zone naphthalene $\left[\ln \left(\mathrm{ng} / \mathrm{m}^{3}\right)\right]$ & 100 & 0.043 & 0.668 \\
Urine 1NAP $[\ln (\mu \mathrm{g} / \mathrm{L})]$ & 104 & 0.080 & 0.418 \\
Urine 2NAP $[\ln (\mu \mathrm{g} / \mathrm{L})]$ & 104 & 0.012 & 0.907 \\
Total urine naphthols $[\ln (\mu \mathrm{g} / \mathrm{L})]$ & 104 & 0.033 & 0.740 \\
Urine naphthalene $[\ln (\mu \mathrm{g} / \mathrm{L})]$ & 104 & 0.184 & 0.061 \\
\hline
\end{tabular}

Note: $n=$ number of fuel-cell maintenance workers. 


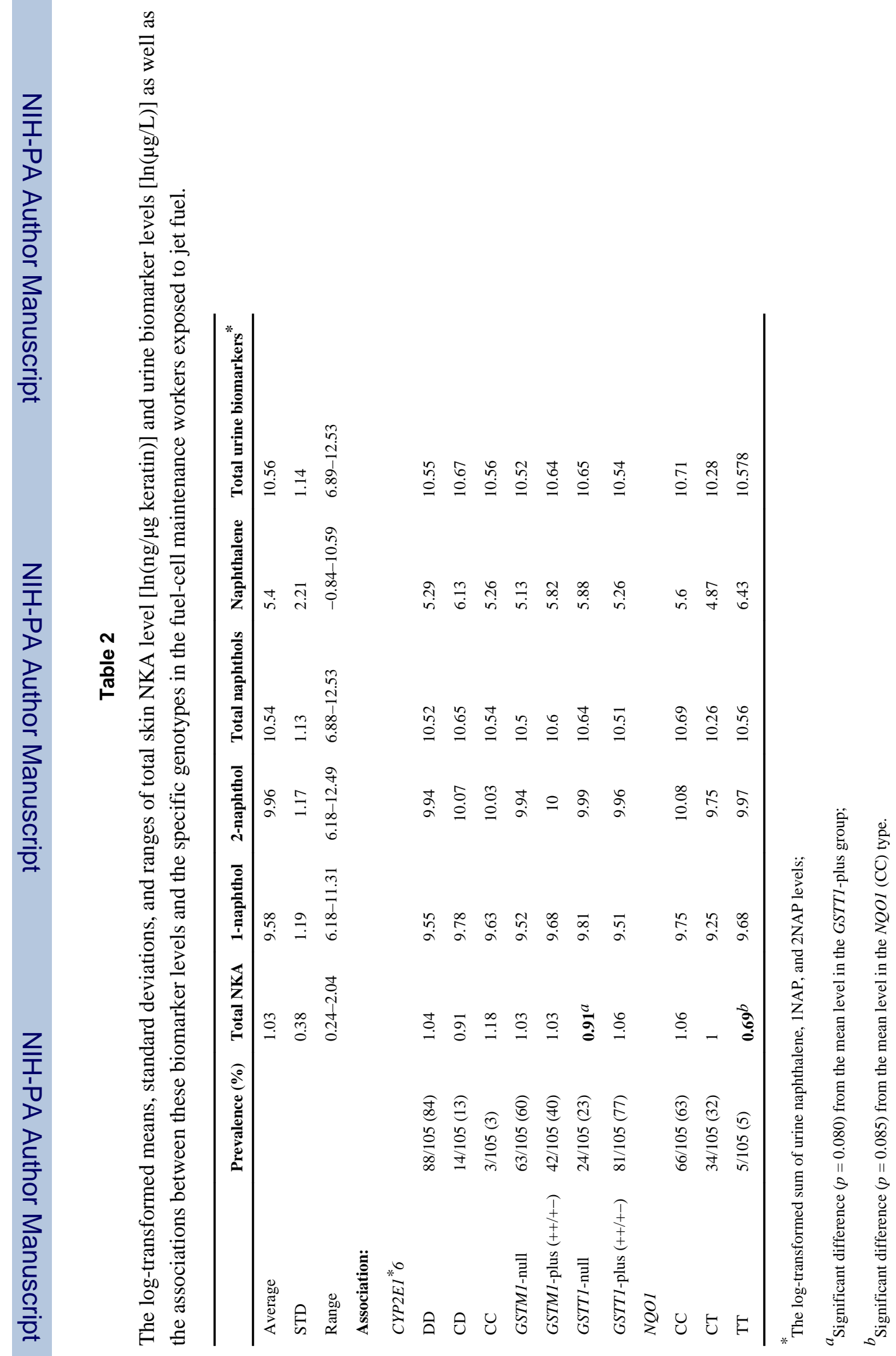




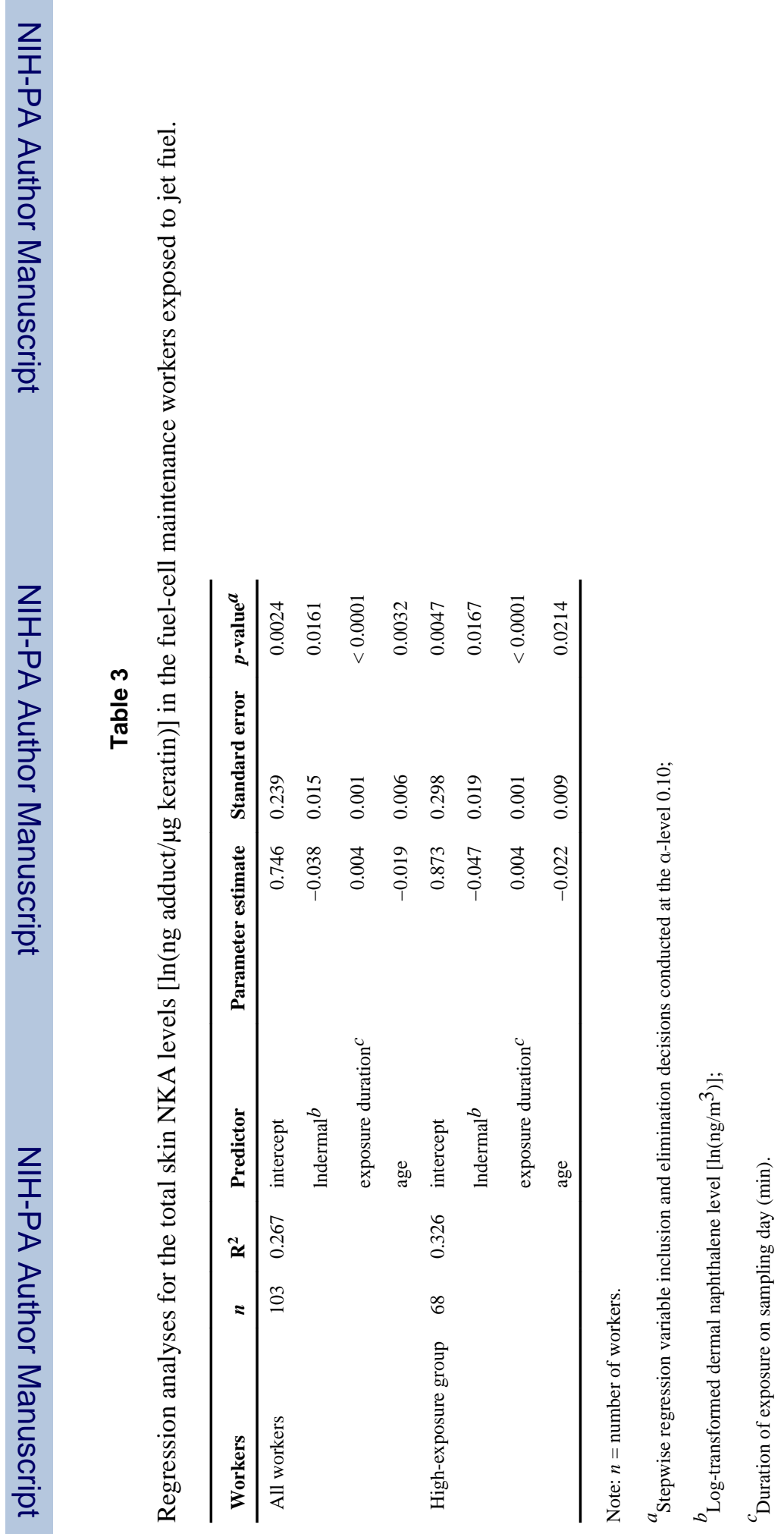




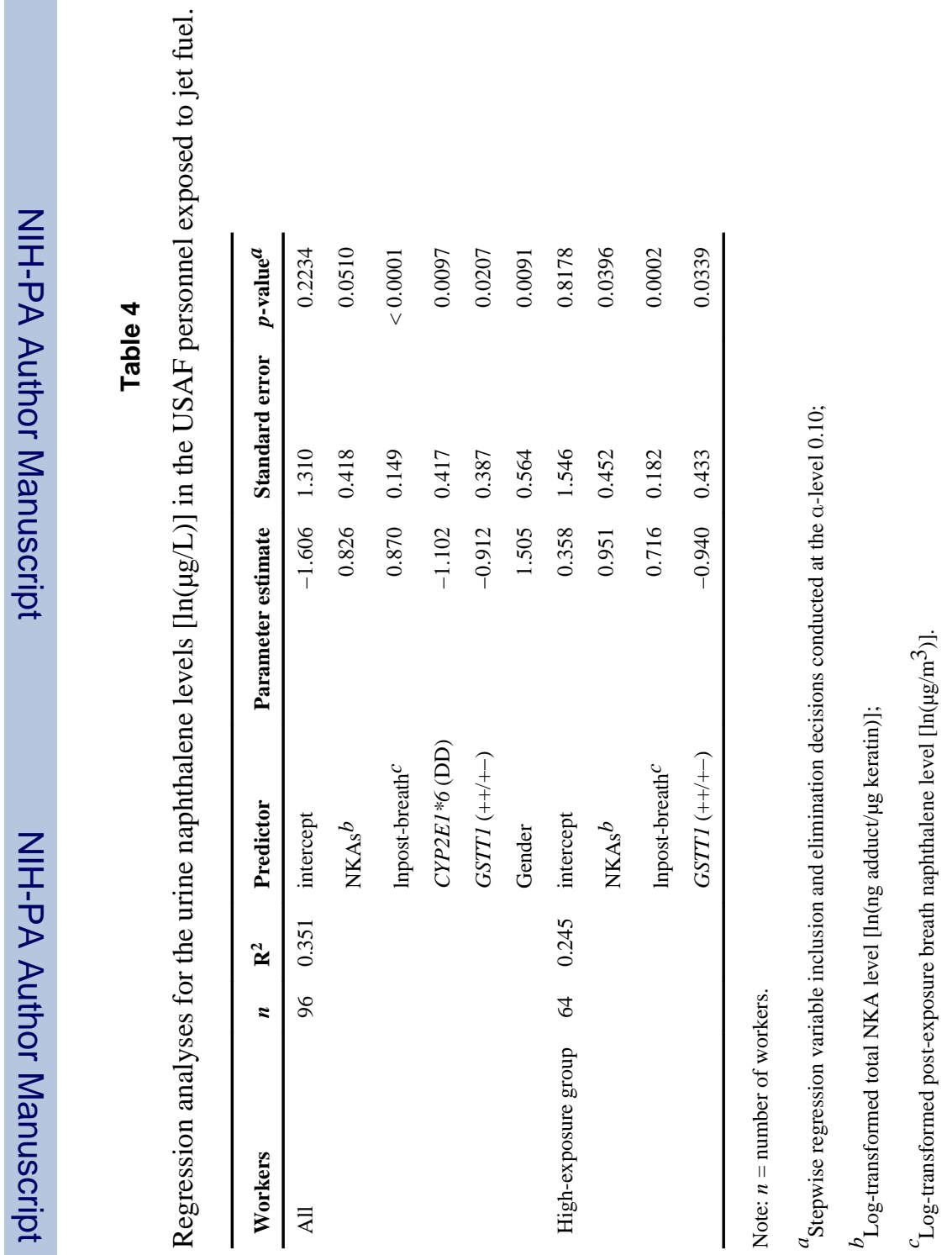

